\title{
Anticipation and adaptation of subjective well-being to marriage in South Africa
}

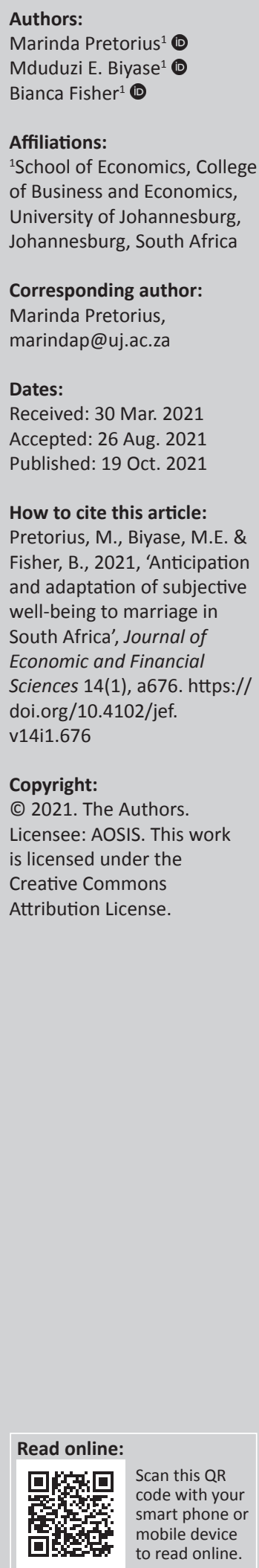

Orientation: The subjective well-being (SWB) of individuals depend inter alia on their personality and life events that occur like marriage. Studies show that individuals exhibit anticipation and adaptation effects before and after a marriage takes place.

Research purpose: The study determined if males and females in South Africa exhibit anticipation and adaptation effects in SWB before and after a marriage takes place.

Motivation for the study: Married individuals generally have higher levels of life satisfaction. Yet four out of 10 marriages in South Africa end in divorce before their 10th anniversary.

Research design, approach and method: The study employed panel estimation methods and used the first five waves of the National Income Dynamic Study (NIDS) to test for the existence of anticipation and adaptation to marriage in South Africa.

Main findings: There is a strong positive impact on SWB when a marriage takes place. This contemporaneous effect of marriage is slightly larger for men than for women. Men exhibit longer anticipation effects before and both genders adapt immediately after the event.

Practical implications: South Africans generally react positively to marriage but then quickly adapt back to hedonic neutrality.

Contribution: Very few studies have investigated adaptation and anticipation trends in a panel setting. Moreover, many of the studies have been conducted in developed countries, implying that the estimates derived from these studies might be influenced by the norms and values of the countries in question.

Keywords: subjective well-being; marriage; adaptation; anticipation; National Income Dynamic Study.

\section{Introduction}

According to the hedonic treadmill theory, developed in 1971 by Brickman and Campbell, individuals react to good and bad life events, but then quickly adapt back to hedonic neutrality. The theory, which has gained widespread acceptance in recent years, argues that regardless of what happens in people's personal lives, their level of happiness ${ }^{1}$ will eventually return back to a baseline level of subjective well-being (SWB). The idea is that events such as marriage cause an initial spike in happiness, but then as time goes on, the reactionary feeling starts to dissipate and habituation inevitably kicks in (Brickman \& Campbell 1971).

The majority of studies that examine the relationship between marital status and SWB, mostly find that married individuals report significantly higher levels of life satisfaction than those who are single, separated, divorced or widowed (see international studies by Blanchflower \& Oswald 2004; Diener et al. 1999; Dupre, Beck \& Meadows 2009; Lawrence et al. 2019 and South African studies by Blaauw \& Pretorius 2013; Botha \& Booysen 2013). This is a well-known finding in literature and is unsurprising given that marriage provides several advantages including emotional and financial support. More recently, studies have begun to examine the longitudinal nature of married individuals' SWB by investigating its' changes leading up to and following the year that couples get married (i.e. anticipation and adaptation). However, this is an area of research that is not well-established, particularly in South Africa. Such an analysis is necessary within the South African context given the simultaneous rise in civil marriages and divorces from 2015 to 2016 (by $0.6 \%$ and $0.3 \%$, respectively) (StatsSA 2018). According to a report by Statistics South Africa, 4 out of 10 marriages end in divorce before their 10th anniversary (StatsSA 2018). This is worrisome and maybe, at least to some degree, reflective of the true reality of marriage - the 'honeymoon' stage sometimes quickly disappears and happiness eventually returns back to its baseline level.

1.Consistent with other studies, we use the words 'subjective well-being' life satisfaction' and 'happiness' interchangeably. 
To test the hedonic treadmill theory, a number of longitudinal studies have examined the anticipation and adaptation effect of SWB to marriage and found that, on average, individuals fully adapt to marriage (Clark et al. 2006, 2008; Frijters, Johnston \& Shields 2011; Qari 2014). However, to the best of our knowledge, no study has examined the anticipation and adaptation effect of SWB to a particular life event in South Africa. Therefore, the contribution of this research is twofold. Firstly, we contribute to the international literature by incorporating the dynamic nature of SWB into the empirical analysis. This is important because, whilst previous studies have accounted for the longitudinal nature of such 'shocks', they assume that SWB is stationary in itself. Secondly, we contribute to South African literature by examining whether gender differences are evident in the anticipation and adaptation of SWB to marriage.

Against this background, the two central questions of this research are as follows: (1) Does the SWB of males and females return back to its baseline level after marriage? (2) Are there gender differences in the anticipation and adaptation effects of SWB to marriage? To answer this, we use data from the 9-year longitudinal National Income Dynamics Study (NIDS) dataset containing information of over 28000 individuals from 7300 households in South Africa. The NIDS is the first national panel study in South Africa and is conducted by the Southern Africa Labour and Development Research Unit (SALDRU) based at the University of Cape Town's School of Economics and in collaboration with the Department of Planning, Monitoring and Evaluation (DPME). The biennial survey began in 2008, and since then has re-interviewed the same individuals across all five waves spanning over a 9-year period. In order to capture the anticipation, contemporaneous and adaptation effect of marriage on SWB, we include three duration dummies in the fixed effects (FEs) models (i.e. one prior to marriage, one at the time of marriage and one post-marriage). This allows us to distinguish between the changes in SWB that take place before, at the time of, and after marriage. Three main findings emerge from this study. Firstly, we find strong evidence of gender differences in the anticipation of marriage. In particular, we see that the anticipation effect is significantly longer for males than females. This is expected as men typically propose to women and hence need additional time to plan and save (e.g. for an engagement ring, engagement party, etc.) Secondly, we see that for both males and females in South Africa, the degree of adaptation to marriage is quick. Thirdly, and in line with Zimmermann and Easterlin (2006), we find that on average, males and females report higher SWB levels after getting married, than they did before getting married.

The rest of this article is structured as follows: Section 'Literature review' offers a comprehensive review of the literature on marriage and SWB. Section 'Research methodology and design' presents the data and methodology. Section 'Results and discussion' provides the empirical results, and lastly, Section 'Conclusion' concludes.

\section{Literature review}

According to Suh, Diener and Fujita (1996) theories of SWB can be divided into two main groups. The one group advocates that personalities mainly determine one's SWB as opposed to events or life conditions. The other group suggests that 'SWB is best explained by integrative models that consider both the effects of immediate life circumstances (e.g. objective health) and global personality dimensions' (Suh et al. 1996:1092). Suh et al. (1996) believed that current SWB is based on long-term personality and that life events adjust SWB only temporarily. Their expectations were tested on the data collected from students initially enrolled for a semester course on SWB. The participants also completed a follow-up survey 2 years after the initial survey. The surveys included a range of questions including amongst others the Neuroticism, Extraversion, and Openness (NEO) personality inventory, the NEO five-factor inventory (NEOW, Conscientiousness, and Agreeableness), and the satisfaction with life scale and life events (Suh et al. 1996). Various positive, negative and neutral events (88 in total) were included in the survey. The results supported the dynamic equilibrium model of Headey and Wearing (1989) an individual's SWB is influenced temporarily by life events. Therefore, only recent events affect SWB and those effects die out quickly after the event (Suh et al. 1996).

The relationship between SWB and marital status is explored in a study by Lucas et al. (2003). According to the authors, there are three main explanations that describe the relationship between the two variables and theories of adaptation, namely, selection hypothesis, social role and event explanation. The selection hypothesis dictates that specific people experience marital events because of certain psychological features (Mastekaasa 1992). Happy people could be more likely to be outgoing and charming which could lead to more success in attracting a partner and getting married (Lucas et al. 2003). According to Mastekaasa (1994), social role clarification refers to the particular forms of hardships that are selectively associated with marital events. For example, people who are divorced will most likely have fewer social networks and an increased probability of financial difficulties as opposed to married people (Lucas et al. 2003). Differences in SWB can be ascribed to these adversities. Lastly, according to the event explanations theory, marital transitions only cause short-term fluctuations in SWB because individuals adapt to the event and then SWB should return to its original levels (Lucas et al. 2003).

In addition, Lucas et al. (2003) identified three phases in the marriage process. The pre-marriage period is known as the baseline phase, the period just before and after the event takes place is the reaction phase, and finally the period after the reaction phase is known as the adaptation phase. A multilevel modelling approach was utilised in the study. Their results showed that when only average trends are considered, individuals responded to marital events and then adjusted back to baseline levels. However, when individual reactions are investigated, there were significant differences in the results. 
Clark et al. (2006) investigated adaptation in life satisfaction before, during and after six specific life and labour market events - unemployment, marriage, divorce, widowhood, the birth of a first child and layoff. They made use of German panel data from 20 waves of the German Socio-Economic Panel (GSOEP). The results showed that individuals return to a baseline level of well-being after divorce, widowhood, the birth of a first child and layoff (Clark et al. 2006). Furthermore, there were some adaptations to marriage, although it was not complete because the results showed positive long-run effects of marriage (Clark et al. 2006).

Angeles (2010) investigated the adaptation and anticipation effects of life events in the United Kingdom. According to the adaptation hypothesis, SWB may temporarily increase or decrease after a life event but individuals will soon adapt to their circumstances and then SWB will return to its former level (Angeles 2010). Angeles (2010) tested for anticipation and adaptation effects by investigating the consequences of various life events (including marriage) on men and women respectively in the British Household Panel Survey. The results for the marriage life event show that it has a positive effect on SWB and that this effect is significantly greater for women than for men. Furthermore, there is no anticipation effect experienced by men whereas women experience the effect at least 1 year before marriage (Angeles 2010). According to Angeles (2010), complete adaptation is experienced by both genders although the process is slower for women than for men.

In addition to hedonic adaptation or habituation - an adaptation of SWB to several life events including marriage - Bottan and Truglia (2011) proposed a general habituation channel in their research by including a lag of happiness in their models. General habituation refers to present instances of happiness (or unhappiness) which are followed by future feelings of happiness (or unhappiness), irrespective of the factor that initially caused the spark in happiness (or unhappiness) (Bottan \& Truglia 2011). The authors made use of dynamic fixed-effect models with data from the GSOEP, the Japanese panel survey of consumers, the British household panel survey and the Swiss household panel (Bottan \& Truglia 2011). The results found evidence of strong habituation of SWB to specific events including unemployment and marriage. Furthermore, their results proved the inertial nature of happiness or the adaptation of happiness to itself-'having greater feelings of happiness in the past directly increases the probability of feeling happy in the present' (Bottan \& Truglia 2011:232).

Frijters et al. (2011) examined the anticipation, adaptation and selection effect of a number of life events on life satisfaction by making use of quarterly Australian panel data (six waves from the Household, Income and Labour Dynamics in Australia [HILDA] survey is utilised). They made use of Ordinary Least Squares (OLS) and FE methods on standard life satisfaction equations controlling for individual characteristics and life events. The results from the study show confirmation of the selection effect, especially for financial troubles, getting fired, separation from a partner and death of a spouse or child (Frijters et al. 2011). According to Frijters et al. (2011:198) 'bad things happen to those already unhappy and good things to those already happy'. Furthermore, the results also show strong evidence of anticipation effects - respondents anticipate good and bad events. In terms of adaptation effects, Frijters et al. (2011) show that respondents exhibit adaptation to most key life events.

In a study that investigates the association between marital status and life satisfaction amidst South Africans, Botha and Booysen (2013) make use of NIDS data from the first wave of the survey and show with ANOVA and ordered probit models that life satisfaction is significantly higher for married individuals than for any other marital status. The study also concluded that there are gender differences in the life satisfaction dynamics of individuals (Botha \& Booysen 2013). The result shows that 'marriage provides well-being benefits for women, whereas non-marriage factors predominantly determine male well-being' (Botha \& Booysen 2013:173).

In another study based on the GSOEP, Qari (2014) investigated whether a marriage has a permanent positive effect on the SWB of an individual. Because of the long timespan that is covered over the 23 waves of the GSOEP, the researchers were able to distinguish between short-term spikes that are normally prevalent in the period shortly before and after marriage and long-term benefits of marriage. Qari (2014) highlighted that it is plausible that individuals will exhibit increased happiness before the marriage takes place because they will likely be in a stable relationship for a certain time period before they get married. During this time period, individuals are still technically single and may live in separate households, but will already be enjoying the benefits of having a partner (Qari 2014). The FE and OLS results of the study which distinguish between males and females, confirm that both sexes enjoy the rewards of having a partner about 2 years before getting married, but males enjoy these benefits for as long as 4 years before getting married. A similar result was confirmed in the study by Clark et al. (2006) whereby it was shown that this 'anticipation' effect is longer for males than females. Qari (2014) also concluded that there exists partial adaptation to marriage because happiness tends to decrease after a year of marriage. However, this postmarriage SWB level is still higher than the level when the respondent was single.

Rudolf and Kang (2015) specifically tested for differences in anticipation and adaptation effects to major life and labour events between males and females in South Korea where moderately strong gender roles are still present. According to Rudolf and Kang (2015), most studies find that women and men react in comparable ways to major life and labour events. The study makes use of the Korean Labour and Income Panel Study (KLIPS) from 1998 to 2008 and includes six major life events (including marriage). The results show that anticipation effects are mostly absent in the data. It was only statistically significant for both genders for unemployment events and for men before 
the birth of the first child. In terms of adaptation, women display a significant positive effect in the first year after marriage. A year after the event, the positive effect halves for women before it contracts completely after 2 years. Although the results are similar for men in the short-run (with a strong positive effect in the first year after marriage which diminishes in the second year), the SWB of men regains power 3 years after the event and in the periods tested beyond that (Rudolf \& Kang 2015). Women, therefore, return to their baseline of SWB whereas men stay on the higher level of SWB during their marriage.

The literature on the relationship between marriage and the SWB of individuals shows indecisive results in terms of anticipation effects. Previous studies have found that women tend to exhibit anticipation effects before marriage. Another study showed that anticipation effects are stronger for men than women whilst another study exhibited no anticipation effects for males. In respect of adaptation, most studies confirm some form of adaptation to marriage. The adaptation effects range from partial to full adaptation. It seems that people either completely adapt to marriage by returning to their previous baseline levels of SWB or that they partially adapt with remaining positive effects on SWB. The only other study that focused on South Africa specifically showed that there are SWB benefits for women when married but the SWB of men is influenced by other factors not related to marriage.

The next section will discuss the data employed in this study as well as the methodology used for the econometric models.

\section{Research methodology and design}

To understand the extent to which individuals adapt to marriage, the first five waves (2008 through 2017) of the NIDS are employed. The first wave of NIDS began in 2008, with each consecutive wave being conducted approximately 2 years apart, that is wave 2 in 2010-2011, wave 3 in 2012, wave 4 in 2014-2015 and wave 5 in 2017. Since 2008, NIDS has been re-surveying the same representative sample of South African individuals, collecting information on income, happiness, migration, labour market participation, economic activity, human capital formation, health, education, vulnerability, and social capital. The first wave of the NIDS data in 2008 contained 7305 households and 28000 individuals (NIDS 2008). The key advantage of this panel data is that it provides unique information on how individuals or households cope with positive or negative shocks by tracking changes in the wellbeing over time. More importantly (for this study), it includes a single self-reported life satisfaction question that asks individuals to rank their satisfaction with life. The question used as a measure of SWB is framed as follows: 'Using a scale of 1 to 10 where 1 means "very dissatisfied" and 10 means "very satisfied", how do you feel about your life as a whole right now?' This question forms the foundation of our empirical analysis.

In addition to our dependent variable, a number of covariates that are important determinants of SWB are incorporated such as a religious affiliation dummy (if respondent is affiliated to any religion); remittance dummy (if the household receives remittances); a race dummy (if respondent is non-White); a cultural dummy proxied by language (if respondent's home language is non-English); geo-type dummies (urban, farms); perceived health status dummies (very good, good, fair, poor); and provincial dummies (Eastern Cape, Northern Cape, Free State, KwaZulu-Natal, North West, Gauteng, Mpumalanga, Limpopo). Continuous variables include lagged SWB, age, household size and education in years. The lagged SWB variable is included to accommodate for the general habituation channel as discussed in the literature review. Further details of the specific variables used in the empirical model are provided in Table 1. We include several control variables that are regarded as important determinants of SWB in South Africa (see study by Biyase, Fisher \& Pretorius 2020).

The estimated SWB trajectories across the three periods (i.e. prior-event where $t=-2,-1$; at the time of the event where

TABLE 1: Description of dependent and independent variables.

\begin{tabular}{|c|c|c|}
\hline Variables & Type & Description \\
\hline \multicolumn{3}{|l|}{ Dependent variable } \\
\hline Subjective well-being (SWB) & Continuous & $\begin{array}{l}\text { SWB is rated on a scale of } 1-10, \\
\text { where } 1 \text { is very dissatisfied and } 10 \\
\text { is very satisfied }\end{array}$ \\
\hline \multicolumn{3}{|l|}{ Explanatory variables } \\
\hline SWB $(-1)$ & Continuous & Lag of SWB \\
\hline Age & Continuous & Age in years \\
\hline Age-Sq & Continuous & Age squared \\
\hline HH-size & Continuous & $\begin{array}{l}\text { Number of members in the } \\
\text { household }\end{array}$ \\
\hline Education & Continuous & Education in years \\
\hline Religious affiliation & Dummy & $\begin{array}{l}1=\text { If affiliated to any religion, } \\
0=\text { Otherwise }\end{array}$ \\
\hline Remittance & Dummy & $\begin{array}{l}1=\text { If the household receives } \\
\text { remittances, } \\
0=\text { Otherwise }\end{array}$ \\
\hline \multicolumn{3}{|l|}{ Race dummy (Whites omitted) } \\
\hline Non-White & Dummy & $1=$ Non-White, $0=$ Otherwise \\
\hline \multicolumn{3}{|c|}{ Cultural dummy (English omitted) } \\
\hline Language non-English & Dummy & $\begin{array}{l}1=\text { If respondents home language } \\
\text { is non-English, } 0=\text { Otherwise }\end{array}$ \\
\hline \multicolumn{3}{|c|}{ Geo-type dimensions (Traditional areas omitted) } \\
\hline Urban & Dummy & Household in urban areas \\
\hline Farm & Dummy & Household in farm areas \\
\hline \multicolumn{3}{|c|}{ Perceived health status (excellent omitted) } \\
\hline Very good & Discrete & $\begin{array}{l}\text { Respondents' health status is } \\
\text { perceived to be very good }\end{array}$ \\
\hline Good & Discrete & $\begin{array}{l}\text { Respondents' health status is } \\
\text { perceived to be good }\end{array}$ \\
\hline Fair & Discrete & $\begin{array}{l}\text { Respondents' health status is } \\
\text { perceived to be fair }\end{array}$ \\
\hline Poor & Discrete & $\begin{array}{l}\text { Respondents' health status is } \\
\text { perceived to be poor }\end{array}$ \\
\hline \multicolumn{3}{|c|}{ Provincial dimensions (Western Cape omitted) } \\
\hline Eastern Cape & Dummy & Household in Eastern Cape \\
\hline Northern Cape & Dummy & Household in Northern Cape \\
\hline Free State & Dummy & Household in Free State \\
\hline KwaZulu-Natal & Dummy & Household in KwaZulu-Natal \\
\hline North West & Dummy & Household in North West \\
\hline Gauteng & Dummy & Household in Gauteng \\
\hline Mpumalanga & Dummy & Household in Mpumalanga \\
\hline Limpopo & Dummy & Household in Limpopo \\
\hline
\end{tabular}

Source: Biyase, M., Fisher, B. \& Pretorius, M., 2020, Remittances and subjective well-being: A static and dynamic panel approach to single-item and multi-item measures of happiness, Economic Development and Well-being Research Group Working Paper Series edwrg-042020, University of Johannesburg, College of Business and Economics. 
$t=0$; post-event where $\mathrm{i}=1,2,3$ ) for males and females, respectively are displayed (Figures 1 and 2 ). What stands out in the two figures is that, regardless of gender, SWB levels increase before marriage, and then fall after marriage, but does not return back to its original levels. Rather, the SWB levels of both males and females are higher after getting married $(i=1,2,3)$ than they were prior to getting married $(\mathrm{i}=-2,-1)$. The peak effect appears to be located at time $t=0$, when the event itself actually occurs. Psychologists (Johnson $\& W u$ 2002) and economists (Lucas et al. 2003) view this

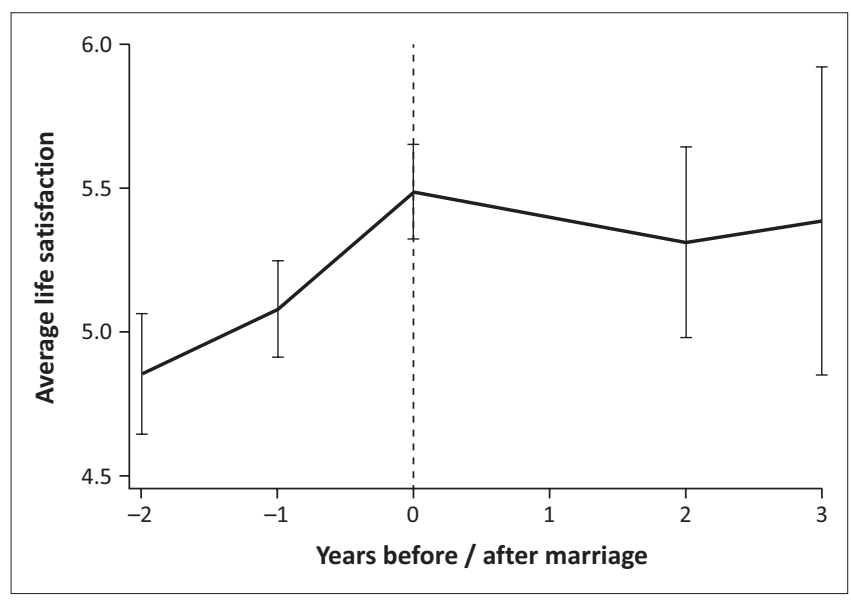

FIGURE 1: Subjective well-being before and after year of marriage for males, 2008-2017.

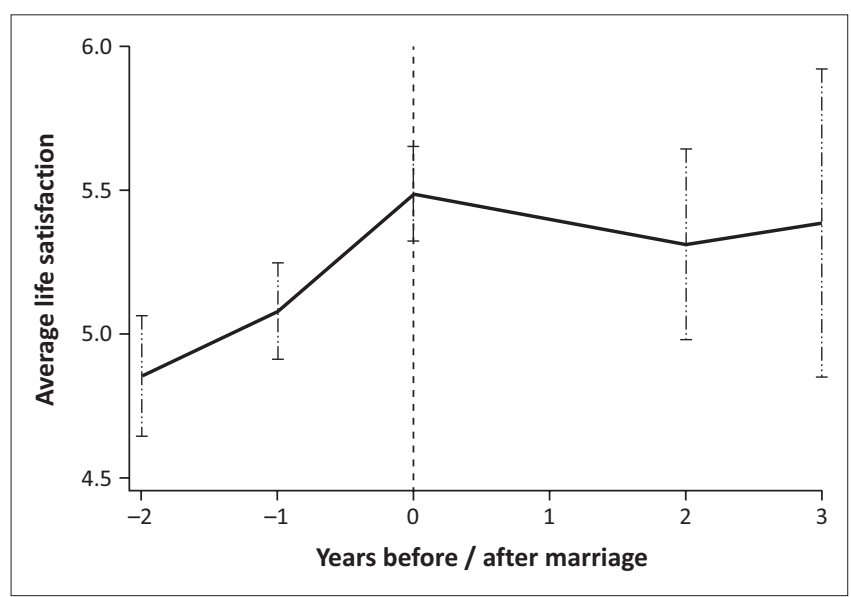

FIGURE 2: Subjective well-being before and after year of marriage for females, 2008-2017. pattern as evidence of adaptation - the view that life events (such as marriage), have only a temporary impact on individual SWB.

To investigate the effects of marriage on SWB in terms of anticipation and adaptation, an approach proposed by Angeles (2010) is followed and model (1) is estimated:

$$
\begin{aligned}
S W B_{i t}= & \alpha_{i}+\varphi_{i}+\Sigma \beta X_{i t}+\Sigma_{s=-2}^{-1} \theta_{s} m_{s i t}+\theta_{0} m_{0 i t}+ \\
& \Sigma_{s=1}^{3} \theta_{s} m_{s i t}+\mu_{i t}
\end{aligned}
$$

where the dependent variable is denoted by $S W B_{i t}, i$ and $t$ represent an individual and time respectively, $X$ is a set of control variables (as described in the preceding paragraphs), $\beta$ is a set of parameters associated with the vector of control variables. $m_{0 i t}$ is a dummy variable taking the value of 1 if individual $i$ marries in year $t$, with $\theta_{0}$ capturing the contemporaneous effect of marriage on $S W B . m_{s i t}$ is an anticipation and adaptation variable. $\theta_{s=-2,-1}$ and $\theta_{s=1,2,3}$ differentiate between the two changes on SWB that take place before and after marriage, that is the anticipation and adaptation effect. $\mu_{i t}$ is a normally distributed error term. The marital status dummy was removed from the vector of control variables $X$ to cope with the multicollinearity bias.

\section{Results and discussion}

The SWB transition dynamics of married individuals in 2008 and 2017 are presented (Table 2). The rows display the transition of married individuals' level of SWB in 2008 and the columns in 2017. The diagonal line represents married individuals who rated the same life satisfaction score in both 2008 and 2017. All values lying above the diagonal line represent the percentage of married individuals whose life satisfaction score increased from 2008 to 2017 (i.e. upward transition). All the values lying below the diagonal line represent the percentage of married individuals whose life satisfaction score decreased from 2008 to 2017 (i.e. downward transition). A similar understanding can be applied to the transition dynamics tables presented in Appendix 1 which contain different waves of NIDS.

For example, the value in row 1 and column 1 (5.77\%) shows the percentage of married individuals that rated a life

\begin{tabular}{|c|c|c|c|c|c|c|c|c|c|c|c|}
\hline \multirow[t]{2}{*}{ Wave 1 (2008) } & \multicolumn{11}{|c|}{ Wave 5 (2017) } \\
\hline & 1 & 2 & 3 & 4 & 5 & 6 & 7 & 8 & 9 & 10 & Total \\
\hline 1 & 5.77 & 4.81 & 11.54 & 24.04 & 21.15 & 9.62 & 8.65 & 10.58 & 1.92 & 1.92 & 100 \\
\hline 2 & 4.35 & 6.52 & 6.52 & 17.39 & 19.57 & 6.52 & 6.52 & 17.39 & 8.7 & 6.52 & 100 \\
\hline 3 & 7.69 & 3.42 & 10.26 & 11.97 & 19.66 & 15.38 & 9.40 & 10.26 & 1.71 & 10.26 & 100 \\
\hline 4 & 3.50 & 3.00 & 12.5 & 15.50 & 19.00 & 14.5 & 13.5 & 9.00 & 3.50 & 6.00 & 100 \\
\hline 5 & 4.07 & 2.62 & 10.17 & 11.92 & 18.31 & 14.83 & 13.66 & 13.66 & 4.36 & 6.40 & 100 \\
\hline 6 & 1.15 & 5.73 & 7.25 & 10.69 & 20.99 & 12.6 & 15.65 & 11.07 & 4.96 & 9.92 & 100 \\
\hline 7 & 3.51 & 3.51 & 11.84 & 12.28 & 20.61 & 8.33 & 12.28 & 13.16 & 4.82 & 9.65 & 100 \\
\hline 8 & 2.97 & 3.96 & 4.46 & 11.88 & 17.33 & 16.34 & 14.36 & 13.86 & 5.94 & 8.91 & 100 \\
\hline 9 & 2.78 & 0.00 & 2.78 & 6.94 & 16.67 & 15.28 & 18.06 & 16.67 & 9.72 & 11.11 & 100 \\
\hline 10 & 2.03 & 1.35 & 6.76 & 9.46 & 15.54 & 12.84 & 11.49 & 16.89 & 10.81 & 12.84 & 100 \\
\hline Total & 3.48 & 3.48 & 8.94 & 12.65 & 18.98 & 13.12 & 13.06 & 12.77 & 5.17 & 8.36 & 100 \\
\hline
\end{tabular}

TABLE 2: Subjective well-being transition dynamics, 2008 and 2017 (percentage).

The numbers in bold allows for ease of reference - it shows the respondents with the same level of SWB in the respective waves of NIDS. 


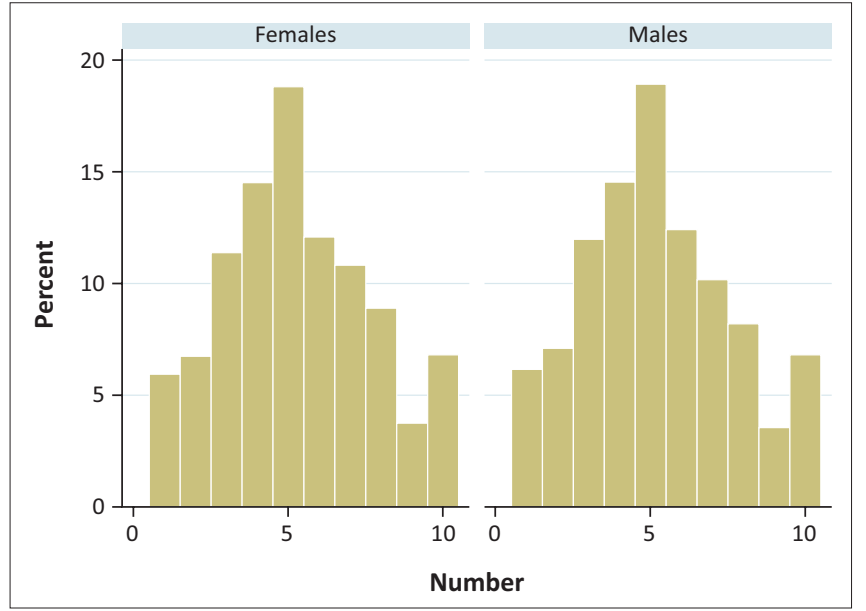

FIGURE 3: Subjective well-being by gender.

satisfaction score of 1 in both 2008 and 2017. Unsurprisingly, we see that the modal score of life satisfaction stagnations is 5 $(18.31 \%)$. This is expected as it is also the mean life satisfaction score of married males and females (as can be seen in Figure 3). It is interesting to see that a substantial percentage of married individuals (12.84\%) were very satisfied with life in both 2008 and 2017 (i.e. rated a life satisfaction score of 10).

The results from the fixed-effect model of possible anticipation and adaptation effects of marriage on the SWB of those getting married in the sample period are presented (Table 3). The table distinguishes between the full sample in the second column and in the third and fourth columns there is a distinction between genders. The relevant specification tests (i.e. Hausman, heteroskedasticity and autocorrelation and a multilinearity tests) were performed and the estimates are reported at the bottom of Table 3. The Hausman test estimates suggest that a FE model should be used for investigating the anticipation and adaptation of SWB to marriage in South Africa. Although the literature on some specification tests such as serial correlation recommends that serial correlation be ignored in short panels (as in our case $-<20$ years) we nonetheless performed serial correlation test using the Wooldridge test and the serial correlation test results indicate that the errors are autocorrelated. To correct for serial correlation, robust and clustered standard errors were estimated. The post-estimation tests of heteroskedasticity based on the Breusch-Pagan/Cook-Weisberg test suggest that there is no heteroscedasticity in the model. The multicollinearity specification test derived from the variance inflation factor (VIF) also reported at the bottom of Table 3 indicate that values for the independent variables are below 5 , implying that there is low risk of multicollinearity.

Considering the coefficients of $\theta_{0}$, it can be seen from Table 3 that there is a strong impact on SWB when a marriage takes place. The positive contemporaneous effect of marriage on SWB is in accordance with other research (Angeles 2010; Rudolf \& Kang 2015). The contemporaneous effect of marriage is slightly larger for men than for women, which agrees with the results of Rudolf and Kang (2015). Angeles (2010) concluded that the effect is greater for women than
TABLE 3: Fixed effect subjective well-being estimates: Anticipation and adaptation to marriage.

\begin{tabular}{|c|c|c|c|c|c|c|}
\hline \multirow{3}{*}{$\begin{array}{l}\text { Variables } \\
\theta_{-2}\end{array}$} & \multirow{2}{*}{\multicolumn{2}{|c|}{$\begin{array}{c}\text { Full Sample } \\
\text { Coef. }\end{array}$}} & \multirow{2}{*}{\multicolumn{2}{|c|}{$\begin{array}{c}\text { Males } \\
\text { Coef. }\end{array}$}} & \multirow{2}{*}{\multicolumn{2}{|c|}{$\begin{array}{c}\text { Females } \\
\text { Coef. }\end{array}$}} \\
\hline & & & & & & \\
\hline & \multicolumn{2}{|c|}{0.458} & 0.629 & $*$ & 0.392 & \\
\hline$\theta_{-1}$ & 0.710 & $* * *$ & 0.808 & $* * *$ & 0.701 & $* * *$ \\
\hline$\theta_{0}$ & 0.576 & $* * *$ & 0.669 & $*$ & 0.561 & $* *$ \\
\hline$\theta_{1}$ & 0.460 & * & 0.576 & & 0.452 & \\
\hline$\theta_{2}$ & 0.565 & & 0.755 & & 0.570 & \\
\hline SWB $(-1)$ & 0.328 & $* * *$ & 0.324 & $* * *$ & 0.324 & $* * *$ \\
\hline Age & -0.054 & $*$ & -0.046 & & -0.073 & $*$ \\
\hline Age-sq & 0.001 & $*$ & 0.000 & & 0.001 & $*$ \\
\hline HH-size & -0.008 & & 0.036 & & -0.024 & \\
\hline Education & 0.011 & & 0.007 & & 0.015 & \\
\hline Re-affiliation & 0.406 & $*$ & 0.269 & & 0.809 & $* *$ \\
\hline Remittance dummy & 0.344 & $* * *$ & 0.594 & * & 0.297 & $*$ \\
\hline \multicolumn{7}{|l|}{ Race dummy (Whites omitted) } \\
\hline Non-white & \multicolumn{2}{|l|}{-0.920} & \multicolumn{2}{|l|}{-0.032} & \multicolumn{2}{|l|}{-0.304} \\
\hline \multicolumn{7}{|c|}{ Cultural dummy proxied by language (English omitted) } \\
\hline Language non-English & \multicolumn{2}{|c|}{-0.222} & -0.176 & & \multicolumn{2}{|l|}{-0.383} \\
\hline \multicolumn{7}{|c|}{ Geo-type dimensions (Traditional areas omitted) } \\
\hline Urban & 0.115 & & 0.167 & & 0.151 & \\
\hline Farms & 0.409 & $*$ & 0.769 & $* *$ & -0.022 & \\
\hline \multicolumn{7}{|c|}{ Perceived health status (Excellent omitted) } \\
\hline Very good & -0.243 & * & -0.269 & & -0.206 & \\
\hline Good & -0.175 & & -0.027 & & -0.224 & \\
\hline Fair & -0.530 & $* *$ & -0.301 & & -0.541 & $*$ \\
\hline Poor & -1.037 & $* * *$ & -0.666 & & -1.118 & $* *$ \\
\hline \multicolumn{7}{|c|}{ Provincial dimensions (WesternCape omitted) } \\
\hline Eastern Cape & -0.461 & & -0.594 & & -0.366 & \\
\hline Northern Cape & -0.062 & & -0.042 & & -0.221 & \\
\hline Free State & -0.279 & & -0.641 & & -0.094 & \\
\hline KwaZulu-Natal & -0.838 & $* * *$ & -0.997 & $* *$ & -0.731 & $* *$ \\
\hline North West & -0.124 & & -0.401 & & -0.128 & \\
\hline Gauteng & -0.725 & $* * *$ & -0.621 & & -0.875 & $* * *$ \\
\hline Mpumalanga & -0.738 & $* * *$ & -1.002 & $*$ & -0.569 & \\
\hline Limpopo & -0.449 & & -0.630 & & -0.361 & \\
\hline Constant & 5.316 & $* * *$ & 5.048 & $* * *$ & 4.468 & $* * *$ \\
\hline Number of observations ( $\mathrm{n}$ ) & - & - & 798 & & 1381 & \\
\hline Adj $R$-squared & - & - & 0.181 & & 0.172 & \\
\hline \multicolumn{7}{|l|}{ Diagnostic Tests } \\
\hline $\begin{array}{l}\text { Breusch-Pagan/Cook-Weisberg } \\
\text { test for heteroskedasticity }\end{array}$ & 0.141 & - & - & - & - & - \\
\hline Wooldridge test for autocorrelation & 0.000 & - & - & - & - & - \\
\hline Multicollinearity test: VIF & 4.110 & - & - & - & - & - \\
\hline Hausman specification test & 0.000 & - & - & - & - & - \\
\hline
\end{tabular}

SWB, Subjective well-being; VIF, variance inflation factor.

for men. According to Botha and Booysen (2013:153) gender differences in results can mainly be ascribed to 'financial gains and healthy behaviour gained from marriage'.

When the full sample is taken into account, the results show that there is a significant anticipation effect $-\theta_{-1}$ is statistically significant one period before the event. When distinguishing between male and female respondents, it can be seen that males experience a longer anticipation period than females. The two periods before the marriage takes place are significant for males $\left(\theta_{-2}\right)$, whereas only the one period before the marriage takes place is significant for female respondents. The extended anticipation period for males is attributed to the tradition where males typically ask females to get married and anticipate the event before females. Positive anticipation effect (albeit not strong) was also confirmed by Clark et al. 
(2006). The results of Angeles (2010) showed that the anticipation effect was completely absent for men whereas women showed anticipation behaviour 1 year before the marriage. Anticipation effects were also absent in the results of Rudolf and Kang (2015).

The full sample shows significant adaptation effects one period after marriage. However, the individual adaptation effects for men and women are very quick as can be seen from the insignificance of the $\theta_{1}$ and $\theta_{2}$ coefficients. Men and women, therefore, adapt immediately after marriage. The results of this study have positive indications of the hedonic treadmill theory which corresponds to the results of Lucas et al. (2003). The adaptation effect was considerably slower for women than for men in the Angeles (2010) study. In the South Korean study, women returned to their baseline SWB level after 2 years and men stayed on a higher level of SWB in the long run (Rudolf \& Kang 2015).

The lag of SWB is statistically significant and positive for the full sample and the gender-specific results. The significant lag of SWB indicates the presence of general habituation as in the study of Bottan and Truglia (2011). The SWB of respondents today is positively influenced by the SWB of respondents in the previous period.

The results from the other explanatory variables included in the study mostly correspond to expectations. The significance of the age and age squared variables (for the full sample and for females) confirm a U-shaped relationship with SWB which is common in happiness studies (see e.g. Blanchflower \& Oswald 2008; Winkelmann \& Winkelmann 1998). The religious affiliation dummy variable shows that for the full sample and for women specifically, being affiliated to any religion has a positive effect on SWB. According to Blaauw and Pretorius (2013) religion augments purpose to an individual's life. The significant relationship between SWB and religion for females was also identified by Moberg (1965). Moberg (1965) ascribed this relationship to the trend that religion plays a more central role in the life of women than with men. The remittance dummy variable corresponds to the findings of Biyase et al. (2020). Remittances have a substantial positive effect on the SWB of individuals, for both males and females.

In terms of household geo-type, the overall results show that individuals located in farm areas exhibit higher SWB than households situated in traditional areas. This tendency was also confirmed in SWB research by Mulcahy and Kollamparambil (2016) who argued that this urban-rural finding is because of false expectations of urban living, as well as, a change in the reference group used to peg individual aspirations. The farm area variable is also specifically significant for male respondents. This gender difference pertaining to household geo-type was also noted in a South African study by Fisher (2019), which found the urban coefficient to be negative and statistically significant only for females. The author noted that a possible explanation for this may be because of the rise of genderbased violence in urban areas, which may similarly be the case in farm areas. Perceived health status was also a significant determinant of SWB. The results show that individuals who perceive their health as 'very good', 'fair' or 'poor' have lower SWB than individuals who perceive their health as 'excellent'. Unlike males, females who perceive their health as 'fair' or 'poor' also have lower SWB than females who perceive their health as 'excellent'. This finding corresponds with those of Fisher (2019) who found that in 2008 and 2017, fair health was not a strong predictor in the SWB of males (albeit not being a strong predictor of female's SWB in 2017).

If the provincial dimensions are considered, it can be seen that SWB in all provinces are lower than the SWB of the Western Cape. However, only the SWB of KwaZulu-Natal, Gauteng and Mpumalanga are significantly lower than that of Western Cape. There have not been many other students that investigate SWB in terms of the different provinces in South Africa. However Blaauw and Pretorius (2013) found that Mpumalanga, Northern Cape and Free State were the provinces with the highest SWB in the country.

\section{Conclusion}

Whilst tests for the existence of anticipation and adaptation to marriage have been undertaken in some developed countries, few attempts if any have been performede for developing countries, especially South Africa. Thus, we tested for the existence of anticipation and adaptation to marriage in South Africa using the first five waves of the National Income Dynamic Study, following the estimation method recently proposed by Angeles (2010). The two central questions of this research were as follows: (1) Does the SWB of males and females return back to its baseline level after marriage? (2) Are there gender differences in the anticipation and adaptation effects of SWB to marriage?

Three main findings emerge from this study. Relating to our research objective 1 , we find that on average, males and females report higher SWB levels after getting married, than they did before getting married. This is in line with Zimmermann and Easterlin (2006). The last two findings both pertain to our research objective 2 in that we find strong evidence of gender differences in only the anticipation of marriage. In particular, we see that the anticipation effect is significantly longer for males than females. This is expected as men typically propose to women and hence need additional time to plan and save (e.g. for an engagement ring, engagement party, etc.). We also see that for both males and females in South Africa, the degree of adaptation to marriage is quick. This is evidence of the hedonic treadmill theory developed by Brickman and Campbell in 1971 which states that individuals react to good and bad life events, but then quickly adapt back to hedonic neutrality. 
Although our results are generally in line with the previous studies, we feel that the measurement of the timing of the event is difficult to pick up because NIDS is completed biennially. According to Frijters et al. (2011):

[S]tudies using aggregated measures of lags and leads (such as yearly lags and leads) will miss a great deal of the action in terms of anticipation and adaptation, and they may substantially underestimate the full effect of any life event. (p. 209)

Moreover, our time dimension is not long enough (only five waves) to adequately capture the adaptation of SWB to marriage over time.

\section{Acknowledgements Competing interests}

The authors declare that they have no financial or personal relationships that may have inappropriately influenced them in writing this article.

\section{Authors' contributions}

All the authors contributed equally to this work.

\section{Ethical considerations}

This article followed all ethical standards for research without direct contact with human or animal subjects.

\section{Funding information}

This research received no specific grant from any funding agency in the public, commercial, or not-for-profit sectors.

\section{Data availability}

The data that support the findings of this study are openly available in DataFirst at https://www.datafirst.uct.ac.za/ dataportal/index.php/catalog/451.

\section{Disclaimer}

The views and opinions expressed in this article are those of the authors and do not necessarily reflect the official policy or position of any affiliated agency of the author.

\section{References}

Angeles, L., 2010, Adaptation and anticipation effects to life events in the United Kingdom, SIRE Discussion Papers 2010-01.

Biyase, M., Fisher, B. \& Pretorius, M., 2020, Remittances and subjective well-being: A static and dynamic panel approach to single-item and multi-item measures of happiness, Economic Development and Well-being Research Group Working Paper Series edwrg-04-2020, University of Johannesburg, College of Business and Economics.

Blaauw, D. \& Pretorius, A., 2013, 'The determinants of subjective well-being in South Africa - An exploratory enquiry', Journal of Economic and Financial Sciences 6(1) 179-194. https://doi.org/10.4102/jef.v6i1.283
Blanchflower, D.G. \& Oswald, A.J., 2004, 'Well-being over time in Britain and the USA', Journal of Public Economics 88(7-8), 1359-1386. https://doi.org/10.1016/S0047 2727(02)00168-8

Blanchflower, D.G. \& Oswald, A.J., 2008, 'Is well-being U-shaped over the life cycle?' Social Science \& Medicine 66(8), 1733-1749. https://doi.org/10.1016/j. socscimed.2008.01.030

Botha, F. \& Booysen, F., 2013, 'The relationship between marital status and life satisfaction among South African adults', Acta Academica 45(2), 150-178.

Bottan, N.L. \& Truglia, R.P., 2011, 'Deconstructing the hedonic treadmill: Is happiness autoregressive?', The Journal of Socio-Economics 40(2011), 224-236. https://doi. org/10.1016/j.socec.2011.01.007

Brickman, P. \& Campbell, D.T., 1971, 'Hedonic relativism and planning the good society', in M.H. Appley (ed.), Adaptation-level theory, pp. 287-305, Academic Press, New York, NY.

Clark, A.E., Diener, E., Georgellis, Y. \& Lucas, R.E., 2006, Lags and leads in life satisfaction: A test of the baseline hypothesis, Institute for the Study of Labo Discussion Paper, No. 2526, Scottish Institute for Research in Economics (SIRE).

Clark, A.E., Diener, E., Georgellis, Y. \& Lucas, R.E., 2008, 'Lags and leads in life satisfaction: A test of the baseline hypothesis', The Economic Journal 118(529), F222-F243. https://doi.org/10.1111/j.1468-0297.2008.02150.x

Diener, E., Suh, E.M., Lucas, R.E. \& Smith, H.L., 1999, 'Subjective well-being: Three decades of progress', Psychological Bulletin 125(2), 276. https://doi. org/10.1037/0033-2909.125.2.276

Dupre, M.E., Beck, A.N. \& Meadows, S.O., 2009, 'Marital trajectories and mortality among US adults', American Journal of Epidemiology 170(5), 546-555. https:// doi.org/10.1093/aje/kwp194

Fisher, B., 2019, 'Subjective well-being: Gender differences in South Africa', Unpublished Master's Minor dissertation, University of Johannesburg.

Frijters, P., Johnston, D.W. \& Shields, M.A., 2011, 'Life satisfaction dynamics with quarterly life event data', Scandinavian Journal of Economics 113(1), 190-211. https://doi.org/10.1111/j.1467-9442.2010.01638.x

Headey, B.W. \& Wearing, A.J., 1989, 'Personality, life events, and subjective wellbeing: Toward a dynamic equilibrium model', Journal of Personality and Social Psychology 57(4), 731-739. https://doi.org/10.1037/0022-3514.57.4.731

Johnson, D.R. \& Wu, J., 2002, 'An empirical test of crisis, social selection, and role explanations of the relationship between marital disruption and psychological distress: A pooled time-series analysis of four-wave panel data', Journa of Marriage and Family 64(1), 211-224. https://doi.org/10.1111/j.1741of Marriage and

Lawrence, E.M., Rogers, R.G., Zajacova, A. \& Wadsworth, T., 2019, 'Marital happiness, marital status, health, and longevity', Journal of Happiness Studies 20(5), 15391561. https://doi.org/10.1007/s10902-018-0009-9

Lucas, R.E., Clark, A.E., Georgellis, Y. \& Diener, E., 2003, 'Reexamining adaptation and the set point model of happiness: Reactions to changes in marital status', Journal of Personality and Social Psychology 84(3), 527-539. https://doi. org/10.1037/0022-3514.84.3.527

Mastekaasa, A., 1992, 'Marriage and psychological well-being: Some evidence on selection into marriage', Journal of Marriage and the Family 54(4), 901-911. https://doi.org/10.2307/353171

Mastekaasa, A., 1994, 'The subjective well-being of the previously married: The importance of unmarried cohabitation and time since widowhood or divorce', Social Forces 73(2), 665-692. https://doi.org/10.2307/2579825

Moberg, D.O., 1965, 'Religiosity in old age', The Gerontologist 5(2), 78-87. https://doi. org/10.1093/geront/5.2.78

Mulcahy, K. \& Kollamparambil, U., 2016, 'The impact of rural-urban migration on subjective well-being in South Africa', The Journal of Development Studies 52(9), 1357-1371. https://doi.org/10.1080/00220388.2016.1171844

NIDS, 2008, Adult questionnaire, National Income Dynamics Survey, SALDRU, UCT School of Economics, Cape Town.

Qari, S., 2014, 'Marriage, adaptation and happiness: Are there long-lasting gains to marriage?', Journal of Behavioral and Experimental Economics 50(2014), 29-39. https://doi.org/10.1016/j.socec.2014.01.003

Rudolf, R. \& Kang, S.J., 2015, 'Lags and leads in life satisfaction in Korea: When gender matters', Feminist Economics 21(1), 136-163. https://doi.org/10.1080/13545701. 2014.967708

Statistics South Africa (StatsSA), 2018, Marriages and divorces 2016, viewed 10 September 2019, from http://www.statssa.gov.za/publications/P0307/P03072016.pdf.

Suh, E., Diener, E. \& Fujita, F., 1996, 'Events and subjective well-being: Only recent events matter', Journal of Personality and Social Psychology 70(3), 1091-1102. https://doi.org/10.1037/0022-3514.70.5.1091

Winkelmann, L. \& Winkelmann, R., 1998, 'Why are the unemployed so unhappy? Evidence from panel data', Economica 65(257), 1-15. https://doi.org/10.1111/14680335.00111

Zimmermann, A.C. \& Easterlin, R.A., 2006, 'Happily ever after? Cohabitation, marriage, divorce, and happiness in Germany', Population and Development Review 32(3), 511-528. https://doi.org/10.1111/j.1728-4457.2006.00135.x 


\section{Appendix 1}

TABLE 1-A1: Subjective well-being transition dynamics, 2008-2010 (percentage).

\begin{tabular}{|c|c|c|c|c|c|c|c|c|c|c|c|}
\hline \multirow[t]{2}{*}{ Wave 1 (2008) } & \multicolumn{11}{|c|}{ Wave 2 (2010) } \\
\hline & 1 & 2 & 3 & 4 & 5 & 6 & 7 & 8 & 9 & 10 & Total \\
\hline 1 & 12.2 & 12.2 & 15.45 & 21.95 & 13.01 & 10.57 & 4.88 & 4.88 & 0.81 & 4.07 & 100 \\
\hline 2 & 12.33 & 9.59 & 20.55 & 10.96 & 20.55 & 5.48 & 10.96 & 8.22 & 0 & 1.37 & 100 \\
\hline 3 & 11.11 & 11.76 & 15.69 & 15.69 & 8.5 & 11.11 & 7.84 & 6.54 & 2.61 & 9.15 & 100 \\
\hline 4 & 12.77 & 11.7 & 12.06 & 13.12 & 20.21 & 11.35 & 6.38 & 3.9 & 2.48 & 6.03 & 100 \\
\hline 5 & 8.57 & 8.16 & 12.04 & 13.47 & 18.16 & 11.43 & 8.78 & 8.98 & 4.9 & 5.51 & 100 \\
\hline 6 & 7.29 & 7.29 & 12.16 & 12.77 & 15.5 & 17.02 & 8.51 & 8.21 & 5.47 & 5.78 & 100 \\
\hline 7 & 4.95 & 4.95 & 7.26 & 12.21 & 22.11 & 16.17 & 9.57 & 9.24 & 5.94 & 7.59 & 100 \\
\hline 8 & 6.41 & 5.69 & 5.34 & 10.68 & 14.59 & 11.74 & 11.03 & 14.95 & 8.54 & 11.03 & 100 \\
\hline 9 & 4.4 & 3.3 & 3.3 & 13.19 & 19.78 & 13.19 & 10.99 & 16.48 & 7.69 & 7.69 & 100 \\
\hline 10 & 5.17 & 5.17 & 7.47 & 6.9 & 16.67 & 17.82 & 10.34 & 9.2 & 5.75 & 15.52 & 100 \\
\hline Total & 8.22 & 7.83 & 10.61 & 12.83 & 17.22 & 13.18 & 8.83 & 8.92 & 4.92 & 7.44 & 100 \\
\hline
\end{tabular}

Note: Sample of married individuals.

The numbers in bold allows for ease of reference - it shows the respondents with the same level of SWB in the respective waves of NIDS.

TABLE 2-A1: Subjective well-being transition dynamics, 2010-2012 (percentage).

\begin{tabular}{|c|c|c|c|c|c|c|c|c|c|c|c|}
\hline \multirow[t]{2}{*}{ Wave 2 (2010) } & \multicolumn{11}{|c|}{ Wave 3 (2012) } \\
\hline & 1 & 2 & 3 & 4 & 5 & 6 & 7 & 8 & 9 & 10 & Total \\
\hline 1 & 5.19 & 13.68 & 12.26 & 12.74 & 20.28 & 11.79 & 8.96 & 8.49 & 3.3 & 3.3 & 100 \\
\hline 2 & 2.96 & 8.37 & 13.3 & 21.18 & 19.7 & 10.34 & 9.36 & 6.9 & 1.97 & 5.91 & 100 \\
\hline 3 & 8.86 & 9.59 & 12.55 & 13.65 & 23.25 & 13.28 & 7.38 & 3.32 & 2.21 & 5.9 & 100 \\
\hline 4 & 5.71 & 12.57 & 8.86 & 18.00 & 14.57 & 15.71 & 8 & 7.71 & 2.57 & 6.29 & 100 \\
\hline 5 & 4.03 & 6.71 & 13.42 & 14.09 & 21.7 & 11.86 & 7.16 & 9.62 & 4.7 & 6.71 & 100 \\
\hline 7 & 3.88 & 5.6 & 11.64 & 12.5 & 16.81 & 9.48 & 12.93 & 12.93 & 5.17 & 9.05 & 100 \\
\hline 8 & 1.81 & 4.52 & 9.05 & 8.60 & 15.38 & 10.41 & 13.57 & 17.19 & 7.24 & 12.22 & 100 \\
\hline 9 & 1.56 & 2.34 & 4.69 & 11.72 & 18.75 & 14.84 & 14.06 & 15.63 & 7.81 & 8.59 & 100 \\
\hline 10 & 0.00 & 5.98 & 9.78 & 8.15 & 15.22 & 10.87 & 15.76 & 17.93 & 5.43 & 10.87 & 100 \\
\hline Total & 4.19 & 7.6 & 11.67 & 13.45 & 18.61 & 12.06 & 10.12 & 10.62 & 4.34 & 7.33 & 100 \\
\hline
\end{tabular}

Note: Sample of married individuals.

The numbers in bold allows for ease of reference - it shows the respondents with the same level of SWB in the respective waves of NIDS.

TABLE 3-A1: Subjective well-being transition dynamics, 2010-2012 (percentage).

\begin{tabular}{|c|c|c|c|c|c|c|c|c|c|c|c|}
\hline \multirow[t]{2}{*}{ Wave 3 (2012) } & \multicolumn{11}{|c|}{ Wave 4 (2014) } \\
\hline & 1 & 2 & 3 & 4 & 5 & 6 & 7 & 8 & 9 & 10 & Total \\
\hline 1 & 4.58 & 6.87 & 6.11 & 17.56 & 16.03 & 14.5 & 14.5 & 9.16 & 1.53 & 9.16 & 100 \\
\hline 2 & 4.25 & 4.72 & 11.79 & 15.09 & 25.94 & 8.49 & 12.74 & 8.02 & 3.3 & 5.66 & 100 \\
\hline 3 & 3.63 & 3.35 & 10.06 & 14.8 & 17.88 & 15.64 & 13.13 & 10.89 & 3.63 & 6.98 & 100 \\
\hline 4 & 3.44 & 4.67 & 9.83 & 12.53 & 20.88 & 9.58 & 13.27 & 10.07 & 5.65 & 10.07 & 100 \\
\hline 5 & 4.30 & 4.48 & 8.26 & 11.88 & 20.14 & 11.36 & 14.63 & 12.56 & 4.30 & 8.09 & 100 \\
\hline 6 & 1.59 & 5.04 & 7.43 & 11.67 & 20.16 & 16.98 & 12.47 & 12.2 & 5.04 & 7.43 & 100 \\
\hline 7 & 2.11 & 2.11 & 7.55 & 14.5 & 19.03 & 11.78 & 14.8 & 16.01 & 4.23 & 7.85 & 100 \\
\hline 8 & 1.85 & 3.38 & 6.15 & 10.46 & 19.08 & 12.92 & 15.69 & 15.08 & 6.46 & 8.92 & 100 \\
\hline 9 & 1.96 & 3.27 & 7.19 & 10.46 & 17.65 & 11.11 & 12.42 & 16.99 & 9.8 & 9.15 & 100 \\
\hline 10 & 0.39 & 1.57 & 6.3 & 9.84 & 16.54 & 10.24 & 15.35 & 19.69 & 7.09 & 12.99 & 100 \\
\hline Total & 2.88 & 3.9 & 8.21 & 12.62 & 19.56 & 12.34 & 13.97 & 12.98 & 5.02 & 8.53 & 100 \\
\hline
\end{tabular}

Note: Sample of married individuals.

The numbers in bold allows for ease of reference - it shows the respondents with the same level of SWB in the respective waves of NIDS. 